\title{
Effects of water immersion on the recovery of upper and lower body anaerobic power following a wrestling session
}

\author{
Asim Cengiz ${ }^{1}$ \\ Mehmet Settar Kocak ${ }^{2}$
}

\begin{abstract}
The aim of this study was to examine effects of cold-water immersion after exercise on powerresponses of wrestlers. Twenty elite male wrestlers were formed by similar age, height, weight and fitness parameters. The wrestling training session included a 60 -minute of vigorous exercise. It consisted of warm-up exercises, standing technical and tactical exercises that mostly allocates arm and leg muscles. Vertical jump height, ropes climb height, and delayed onset of soreness was measured before, after, $24 \mathrm{~h}$ and 48 hors after the wrestling training. Cold-water immersion caused decrements in power loss at each follow-up time in comparison to a thermo neutral immersion. It can be suggested that the longer time needed for power to return to normal levels after cold treatment and assessment of varied contraction types may present a more broad demonstration of muscle function and consequential capacity for dynamic exercise following exercise-induced muscle damage.
\end{abstract}

Keywords: Cold water immersion, power, wrestling.

\section{Introduction}

Sports facilitators currently use many modalities of recovery techniques in an attempt to counteract the negative effects of vigorous exercise. Elite level athletic participation necessitates recovery from various physiological stressors (Leeder et al., 2012; Cheung et al., 2003; Bleakley et al., 2012). Vigorous exercise may also produce exercise induced muscle damage (EIMD) (Bleakley et al., 2012).

EIMD often occurs after unaccustomed exercise, especially after eccentric contractions (Ebbeling and Clarkson, 1989; Proske and Morgan, 2001; Stauber, 1989; Newham et al., 1987). Even though the exact mechanism responsible for damage is not known, previous studies have suggested that the initial disruption to skeletal muscle subsequent exercise is attributed to progressive deterioration of certain myofibrils (Jones et al., 1986).

EIMD is known to cause reductions in maximal strength and performance (Newham et al., 1983; Armstrong, 1984; Armstrong et al., 1991; Cheung et al., 2003). DOMS also results from highintensity work relating eccentric muscular contractions (Knuttgen, 1986; Brassinnea, 2003) that induces muscle damage (Buroker and Schwane, 1987). It is also associated with loss of strength. In an attempt to lessen the symptoms of EIMD, several cryotherapy methods (Howatson et al., 2003)

\footnotetext{
${ }^{1}$ Dr., Middle East Technical University, Faculty of Education, Department of Physical Education and Sports, Ankara, Turkey, awesome77@gmail.com

2 Prof. Dr., Middle East Technical University, Faculty of Education, Department of Physical Education and Sports, Ankara, Turkey, skocak@metu.edu.tr
} 
Cengiz, A., \& Kocak, M. S. (2016). Effects of water immersion on the recovery of upper and lower body anaerobic power following a wrestling session. International Journal of Human Sciences, 13(1), 1402-1407. doi:10.14687/ijhs.v13i1.3364

have been used by sports facilitators (Bleakley et al, 2012). Cryotherapy is anticipated to decrease tissue temperature, diminish inflammation and consequential edema, and reduce time to recovery.

While previous studies confirmed that cold-water immersion is beneficial on recovery of athletes' power (Bailey 2007; Montgomery 2008; Rowsell 2009; Skurvydas 2006, King 2009) in other sports, the findings about the effects of cold-water immersion (CWI) on DOMS is controversial (Kuligowski 1998; Ingram 2009; King 2009; Vaile 2008c, Ingram 2009). Also, there are limited studies providing evidence that cold-water immersion after unaccustomed exercise, intensely if the exercise involves a large amount of muscle lengthening contractions, improves subsequent power recovery of wrestlers. It is clear; therefore, that current literature addressing the treatment of EIMD with cold-water immersion in wrestling is limited and equivocal. Thus, the aim of this study was to explore effects of cold-water immersion after eccentric exercise on lower and upper power, and DOMS responses of wrestlers. It was expected that cold-water immersion exercise would help wrestlers recover faster when compared to thermo natural immersion (TWI).

\section{Methods}

\section{1. Participants and Experimental Design}

The subject characteristics were given in Table 1. Twenty elite male wrestlers voluntarily signed consent form to participate in the study. Each subject was required to complete a health questionnaire designed to screen out possible subjects who were contraindicated for inclusion in the study due to personal or familial health reasons. The purpose and nature of the study was explained to each subject prior to their participation. In addition, each subject read and signed a document that explained in detail the essence of the study. Local ethic committee of the university approved the study protocol. Two athletes from the same weight class served as experiment and control groups. The subjects were formed by similar age, height, weight and fitness parameters.

\subsection{Experimental Design}

Before the exercise test, physical characteristics of subjects (height, weight, and body composition) were measured. The wrestling training session included a 60-minute vigorous exercise. It consisted of warm-up exercises, standing technical and tactical exercises that mostly allocates leg and arm muscles. During the day 1, vertical jump values of the subjects were recorded prior, 30 minutes after, 24 hours after the training. During the day 2, which is after one week, rope climb times values of the subjects were recorded prior, 30 minutes after, 24 hours after the training.

\subsection{Cold water and Thermo neutral immersions}

Instantly subsequent to the training, wrestlers from the CWI group were fully immersed in a stirred cold-water bath for $10 \mathrm{~min}$ (Bailey et al., 2007). The water was maintained at a mean temperature of $10^{\circ} \mathrm{C}$ by the adding of crushed ice. Throughout the time of CWI, wrestlers in the TWI group stayed in the same long-seated position as their cryotherapy counterparts, completely immersing in a water bath at a mean temperature of $35^{\circ} \mathrm{C}$ (Rowsell et al., 2009).

\subsection{Procedures for power measurements}

Rope Climb: The rope climb (RC, $5.1 \mathrm{~m}$ ) test was used to evaluate upper body muscular power and endurance. The test started with the wrestler in a seated position with both hands holding the climbing rope. They were allowed to employ their legs to perform the climb. Time was recorded to the nearest 0.1 second (Callan, 2000)

Vertical Jump: Lower-body muscular power was evaluated using a VJ protocol (Vertec, Questek Corp., Northridge, CA). As soon as assessing initial reach, the wrestlers were required to position 
Cengiz, A., \& Kocak, M. S. (2016). Effects of water immersion on the recovery of upper and lower body anaerobic power following a wrestling session. International Journal of Human Sciences, 13(1), 1402-1407. doi:10.14687/ijhs.v13i1.3364

below the Vertec with his feet shoulder width apart. From this stationary position, the subjects jumped explosively and pushed away as many vanes as possible. The wrestlers were not permitted to take a step. Subsequent to completing a jump, the subjects were given two trials to advance this jump. The number pushed away on the maximum effort was recorded (Callan, 2000). The jump height was calculated as: VJ 5 maximal jump height - initial reach height.

\subsection{Statistical analysis}

Results were analyzed using the SPSS version 22.00 (SPSS Inc., Chicago, USA). The average and standard deviation of all parameters were calculated. It was determined that the data are normally distributed. A repeated (ANOVA) was used to institute differences between treatments over time. For single comparisons, a paired sample $t$-test was used to verify whether there were differences between groups. Statistical significance was accepted at an alpha -level of 0.05.

\section{Results}

There were not any significant differences between age, height, body weight, and BMI values of two groups (Cold-water immersion vs. Thermo neutral immersion).

Table 1. Descriptive statistics for all subjects.

\begin{tabular}{lll} 
& CWI $(\mathrm{N}=10$, Mean $\pm \mathrm{SD})$ & TWI $(\mathrm{N}=10$, Mean $\pm \mathrm{SD})$ \\
\hline Age & $22.40 \pm 2.50$ & $22.87 \pm 2.87$ \\
Height $(\mathrm{cm})$ & $175.76 \pm 6.86$ & $176.23 \pm 5.26$ \\
Body Weight $(\mathrm{kg})$ & $75.78 \pm 8.71$ & $75.34 \pm 9.01$ \\
BMI & $22.02 \pm 4.53$ & $21.26 \pm 2.41$ \\
\hline
\end{tabular}

Data are shown as means $\pm S D$.

The VJ measured lower-body muscular power while the RC test indicated the level of upper-body muscular power and endurance. They were presented in Table 2.

There were not significant differences between the resting vertical jump (VJ) values of two groups. $(\mathrm{P}>0.05)$, but VJ (post) and VJ $(24 \mathrm{~h})$ values were significantly different from each other $(\mathrm{P}<0.05)$. There were not significant differences between the resting RC (rope climb) times of two groups. $(\mathrm{P}>0.05)$, but RC (post) and VJ (24 h) values were significantly different from each other $(\mathrm{P}<0.05)$.

Table 2. Vertical jump and Rope climb before, after 30 minutes, and after 24 hours of exercise.

\begin{tabular}{lllll}
\hline & Treatment & Pre-Training & Post-Training & 24 Hours \\
\hline Vertical Jump & CWI & $54.10 \pm 5.76$ & $52.40 \pm 5.58^{\mathrm{ac}}$ & $53.85 \pm 5.87^{\mathrm{bc}}$ \\
$(\mathrm{cm})$ & TWI & $54.00 \pm 5.89$ & $51.15 \pm 5.20^{\mathrm{a}}$ & $51.03 \pm 5.07^{\mathrm{a}}$ \\
Rope Climb & CWI & $7.87 \pm 1.22$ & $8.52 \pm 1.17^{\mathrm{ac}}$ & $8.31 \pm 1.15^{\mathrm{abc}}$ \\
(sn) & TWI & $7.80 \pm 1.23$ & $9.34 \pm 1.14^{\mathrm{a}}$ & $9.21 \pm 1.03^{\mathrm{a}}$ \\
\hline
\end{tabular}

CWI $=$ Cold water immersion. $\mathrm{TWI}=$ Thermo natural-water immersion.

a Values are significantly different from pre values $(p<0.05)$.

$b$ Values are significantly different from post values $(p<0.05)$.

$c$ Values are significantly different from TWI values $(p<0.05)$. 
Cengiz, A., \& Kocak, M. S. (2016). Effects of water immersion on the recovery of upper and lower body anaerobic power following a wrestling session. International Journal of Human Sciences, 13(1), 1402-1407. doi:10.14687/ijhs.v13i1.3364

\section{Discussion}

This study aimed to inspect the effect of immediate post-exercise CWI on power after $24 \mathrm{~h}$ recovery after a one-wrestling session. It was stated that maximal voluntary force generating capability might be the most interrelated sign of muscle damage (Warren, 1999; Morton et al., 2005). Present study resulted in that CWI reduced power loss at each follow-up time in comparison to a TWI. It was hypothesized that, as a result of cold treatment, vasodilatation and vasoconstriction of the peripheral blood vessels or "pumping action" has been anticipated to increase lactate clearance, increase blood flow (Cochrane, 2004) and consequent reduced the myocellular damage (Vaile, 2007).

It was stated that vertical jump in wrestling is used during many techniques to oppose attacks by the challenger. (Callen, 2000) but not many studies used rope climbing as a routine of assessing upper-body muscular endurance in combative sport athletes except Callen, et al (2000) study. They found similar results as the findings of the present study (9.sec. vs. $8.1 \mathrm{sec}$ ). At 24-hour follow-up, the findings from three studies (Bailey, 2007; Montgomery 2008; Rowsell, 2009) measuring maximal jump height indicated no difference between groups. Only Montgomery 2008 found no differences between groups at 48 hours. Skurvydas (2006) found no differences between groups immediately post intervention, but jump height was considerably superior in the CWI group at 24 hours, 48 hours, and 72 hours follow-up. King (2009) measured the percentage drop in jumping performance during five consecutive jumps; this was significantly lower and in favor of CWI at 24 hours. Several studies also confirmed that cold-water treatment significantly reduced muscle strength reduction at each follow-up time $(6,24,48,72$ and 96 hours) in comparison to passive recovery (Ingram et al., 2009). Maximal strength in three studies Vaile et al. (2008), Kuligowski et al. (1998) Pournot et al. (2011) showed significantly lower changes from baseline in the CWT group. It was also reported that significant decreases in peak quadriceps strength were observed in the TWI group at $24 \mathrm{~h}$ and $48 \mathrm{~h}$ and in the CWI group at $48 \mathrm{~h}$. However, quadriceps strength was significantly greater at $24 \mathrm{~h}$ in the CWI than in the TWI group (Ascensao et al., 2011). It is likely that the disagreements between studies may be attributed to the environment of cryotherapy method and the length of the cold application (Eston and Peters, 1999).

\section{Conclusion}

The present study confirmed that that CWI reduced power loss at each follow-up time in comparison to TWI

\section{References}

Armstrong RB. (1984). Mechanisms of exercise induced delayed muscular soreness: a brief review. Med Sci Sports Exerc, 16, 529-538

Armstrong RB, Warren GL, Warren JA.(1991). Mechanisms of exercise-induced muscle fiber injury. Sports Med, 12,184-207

Ascensao A, LeiteM, Rebelo AN, Magalhaes S, and Magalhaes J. (2011). Effects of cold water immersion on the recovery of physical performance and muscle damage following a one-off soccer match. Journal of Sports Sciences, 29, (3):217-25.

Bailey D M, Erith J, Griffin PJ, Dowson A, Brewer D S, and Gant N (2007). Influence of coldwater immersion on indices of muscle damage following prolonged intermittent shuttle running. Journal of Sports Sciences, 25,1163-1170.

Bleakley C, McDonough S, Gardner E, Baxter GD, Hopkins JT, et al. (2012). Cold-water immersion (cryotherapy) for preventing and treating muscle soreness after exercise. 
Cengiz, A., \& Kocak, M. S. (2016). Effects of water immersion on the recovery of upper and lower body anaerobic power following a wrestling session. International Journal of Human Sciences, 13(1), 1402-1407. doi:10.14687/iihs.v13i1.3364

Cochrane Database Syst Rev, 2: CD008262

Brassinnea E, Poortmans J, Lissassi V, Duchateaux P. (2003). Effect of eccentric hamstring contractions at short and long length on delayed onset muscular soreness (DOMS). Isokinetics and Exercise Science, 11, 59-60

Buroker KJ, Schwane JA. (1987). Does post-exercise static stretching alleviate exercise-induced muscle soreness? Med Sci Sports Exerc, 19, (2) (Suppl): 216A

Bobbert MF, Hollander AP, Huijing PA. (1986). Factors in delayed onset muscle soreness of man. Med Sci Sports Exerc,18, 75-81

Callan SD, Brunner DM, Devolve KL, Mulligan SL, Hesson J, Wilber R. and Kearney LJT. (2000). Physiological Profiles of Elite Freestyle Wrestlers. Journal of Strength and Conditioning Research, 14(2), 162-169

Clarkson PM, Tremblay I. (1988). Exercise induced muscle damage, repair, and adaptation in humans. J Appl Physiol, 65: 1-6

Cheung K, Hume PA, Maxwell L. (2003). Delayed onset muscle soreness; treatment strategies and performance factors. Sports Med, 33, 145-164

Cochrane DJ. (2004). Alternating hot and cold water immersion for athlete recovery: a review. Physical Therapy in Sport, 5, 26-32

Ebbeling CB, Clarkson PM. (1989). Exercise-induced muscle damage and adaptation. Sports Med, 7, 207-234

Eston R, Peters D. (1999). Effects of cold-water immersion on the symptoms of exercise induced muscle injury. J Sports Sci, 17, 231-238

Jones DA, Newham DJ, Round JM, and Tolfree SE. (1986). Experimental human muscle damage: morphological changes in relation to other indices of damage. J Physiol, 19, 375: 435-448

Golden CL, Graves JE, Buchanan P, Dudley G. (1991). Eccentric and concentric strength after repeated bouts of intense exercise. Med Sci Sports Exerc, 23, (Suppl): 655A

Howatson G, van Someren KA. (2003). Ice massage: effects on exercise-induced muscle damage. J Sports Med Phys Fitness, 43, 500-505

Gulick DT, Kimura IF, Sitler M, Paolone A, Kelly JD. (1996). Various treatment techniques on signs and symptoms of delayed onset muscle soreness. J Athl Train, 3, 145-152

Ingram J, Dawson B, Goodman C, Wallman K, and Beilby J. (2009). Effect of water immersion methods on post-exercise recovery from simulated team sport exercise. J Sci Med Sport, $12,417-421$

King M, Duffield R. (2009). The effects of recovery interventions on consecutive days of intermittent sprint exercise. Journal of Strength and Conditioning Research 23, (6):1795802.

Knuttgen HG. (1986). Human performance in high intensity exercise with concentric and eccentric muscle contractions. Int J Sports Med, 7, 6-9

Kuligowski LA, Lephart SM, Giannantonio FP, and Blanc R. (1998). Effect of whirlpool therapy on the signs and symptoms of delayed-onset muscle soreness. J Athl Train, 33, 222-228

Leeder J, Gissane C, van Someren K, Gregson W, and Howatson G. (2012). Cold water immersion and recovery from strenuous exercise: a meta-analysis. Br J Sports Med, 46, 233-240

Montgomery PG, Pyne DB, Hopkins WG, Dorman JC, Cook K, and Minahan CL. (2008). The effect of recovery strategies on physical performance and cumulative fatigue in competitive basketball. Journal of Sports Sciences, 26(11),1135-45.

Morton JP, Atkinson G, MacLaren DP, Cable NT, and Gilbert G. (2005). Reliability of maximal 
Cengiz, A., \& Kocak, M. S. (2016). Effects of water immersion on the recovery of upper and lower body anaerobic power following a wrestling session. International Journal of Human Sciences, 13(1), 1402-1407. doi:10.14687/iihs.v13i1.3364

muscle force and voluntary activation as markers of exercise-induced muscle damage. Eur J Appl Physiol, 94, 541-548

Newham DJ, Jones DA, Clarkson PM. (1987). Repeated high-force eccentric exercise: effects on muscle pain and damage. J Appl Physiol, 63, 1381-1386

Proske U, Morgan DL. (2001). Muscle damage from eccentric exercise: mechanism, mechanical signs, adaptation and clinical applications. J Physiol, 537, 333-345

Pournot H, Bieuzen F, Duffield R, Lepretre PM, and Cozzolino C. (2011). Short term effects of various water immersions on recovery from exhaustive intermittent exercise. Eur J Appl Physiol, 111, 1287-1295

Rowsell, G. J., Coutts, A. J., Reaburn, P., \& Hill-Haas, S. (2009). Effects of cold-water immersion on physical performance between successive matches in high-performance junior male soccer players. Journal of Sports Sciences, 27, 565-573.

Stauber WT. (1989). Eccentric action of muscles: physiology, injury, and adaptation. Exerc Sport Sci Rev, 17, 157-185

Skurvydas A, Sipaviciene S, Krutulyte G, Gailiuniene A, Stasiulis A, and Mamkus G. (2006). Cooling leg muscles affects dynamics of indirect indicators of skeletal muscle damage. Journal of Back and Musculoskeletal Rehabilitation, 19 (4), 141-51.

Warren GL, Lowe DA, Armstrong RB. (1989). Measurement tools used in the study of eccentric contraction-induced injury. Sports Med, 27, 43-59

Vaile JM, Gill ND, Blazevich AJ. (2007). The effect of contrast water therapy on symptoms of delayed onset muscle soreness. J Strength Cond Res, 21, 697-702

Vaile J, Halson S, Gill N, Dawson B. (2008). Effect of hydrotherapy on the signs and symptoms of delayed onset muscle soreness. Eur J Appl Physiol, 102, 447- 455 